\title{
In silico characterisation and homology modelling of toll/toll like receptors (TLRs) from penaeid shrimps
}

\author{
A. ANGELA MERCY, N. HEMAMALINI*, K. ARULJOTHI ${ }^{a}$, B. CHRISOLITE AND \\ K. KARALMARX \\ Institute of Fisheries Post-Graduate Studies, Dr. J. Jayalalithaa Fisheries University, Vaniyanchavadi, Chennai \\ Tamil Nadu, India \\ ${ }^{*}$ Dr. M. G. R. Fisheries College and Research Institute, Dr. J. Jayalalithaa Fisheries University, Thalainayeru \\ Nagapattinam, Tamil Nadu, India \\ e-mail: angelfish4194@gmail.com
}

\begin{abstract}
Toll or Toll-like receptors are conserved receptors, which act as the first line of defense against infection by pathogens. To use Toll/Toll like receptors as drug targets, it is essential to understand their physico-chemical properties and three dimensional structures. In the present study, physico-chemical properties and secondary structure of Toll/Toll like receptors from selected species of penaeid shrimps viz., Penaeus chinensis, P. vannamei, P. monodon and P. japonicus were computed using online servers. Three dimensional structure was predicted by homology modelling using different softwares, SWISSMODEL, Phyre2 and Geno3D softwares were validated using online tools to find the best model for the protein under study. From the physicochemical properties, nature of the Toll/Toll like receptor protein was revealed as acidic, thermostable, hydrophobic and transmembrane protein. Structural analysis indicated the presence of alpha helices and random coils as predominant elements followed by extended stands and beta turns. Three dimensional structures predicted using SWISSMODEL was validated as extremely good model using Protein Quality Predictor online server.
\end{abstract}

Keywords: Homology modelling, In silico, Physico-chemical properties, Secondary structure, Shrimp, Toll like receptors

\section{Introduction}

Penaeid shrimp culture is one of the economically important aquaculture sectors in the world. Even though shrimp farming holds crucial position in the rapidly growing aquaculture sector, disease occurrence in the culture systems continue to devastate the industry. To tackle bacterial pathogens causing deadly diseases, antibiotics are used which results in development of antibiotic resistance (Karunasagar et al., 1994). In order to develop novel strategies to restore the health of the animal, knowledge of innate immune system is necessary (Dechamma et al., 2015) since the shrimp immunity primarily depends on innate immunity (Loker et al., 2004). Pattern recognition is the first step of innate immunity in which pattern recognition receptors (PRRs) sense the presence of infection on the basis of pathogen associated molecular patterns (PAMPs) and activate immune responses. To date, 11 types of PRRs have been identified in shrimp (Wang et al., 2013). Among several PRRs, Toll like receptors (TLRs) play a major role in recognition of pathogens in shrimp (Deepika et al., 2014). TLRs have been reported from Penaeus chinensis, P. vannamei, P. monodon and P.japonicus (Arts et al., 2007; Mekata et al., 2008; Yang et al., 2008; Wang et al., 2012).
TLRs recognise bacterial and viral components with the help of PAMPS-PRRs (Beutler, 2004). TLRs are reported to show upregulation in response to bacterial pathogens (Wang et al., 2013). Upon recognition of their ligands on microorganisms, TLRs induce the expression of a variety of host defense genes, such as inflammatory cytokines and chemokines, antimicrobial peptides and other effectors against the invading pathogens (Chen et al., 2016). These TLRs can be targeted for drug development (Krishnan et al., 2009). There is great potential in using adjuvancy effect of TLR agonists. Vaccination using TLR agonists as adjuvant may enhance the efficacy of vaccines by faster and stronger immune responses to the pathogen (Patel et al., 2014). It becomes necessary to determine the structure of the drug target in drug discovery. Besides all aspects of experimental analysis, nowadays several online servers provide opportunities for the analysis and characterisation of protein to gain momentum. Instead of trying to characterise the structure of proteins experimentally, computational methods can be used to predict the structure using known representative structures. These computational tools pave way to understand physico-chemical properties and structural features of a protein in a cost effective way with in a short period of time. 
In the present study, physico-chemical properties viz., molecular weight, isoelectric point (pI), extinction co-efficient (EC), instability index (II), aliphatic index (AI), grand average hydropathicity (GRAVY) and homology modelling of Toll/TLRs from 4 species of penaeid shrimps were studied.

\section{Materials and methods}

\section{Retrieval of protein sequences}

Toll/TLR protein sequences were retrieved from the National Centre for Biotechnological Information (NCBI) Protein database. A total of 4 Toll/TLRs sequences of penaeid shrimps were retrieved in FASTA format. Details of the sequences used in this study are given in Table 1.

Table 1. Toll/TLRs retrieved from NCBI protein database

\begin{tabular}{lll}
\hline Accession no. & Description & Species \\
\hline ACC68670.1 & Toll-like receptor & Penaeus chinensis \\
ROT75501.1 & Toll-like receptor & Penaeus vannamei \\
ABO38434.1 & Toll receptor & Penaeus monodon \\
BAF99007.1 & Toll receptor & Penaeus japonicus \\
\hline
\end{tabular}

\section{Characterisation of physico-chemical properties}

Physico-chemical parameters of the selected protein sequences such as aminoacid composition, molecular weight, theoretical isoelectric point $(\mathrm{pI})$, total number of positive (Arg+Lys) and negative (Asp+Glu) residues $(+\mathrm{R} /-\mathrm{R})$, extinction co-efficient (EC) (Gill and Hippel, 1989), instability index (II) (Guruprasad et al., 1990), aliphatic index (AI) (Ikai, 1980) and grand average hydropathicity (GRAVY) (Kyteand Doolittle, 1982) were computed using ExPASyProtParam tool (Gasteiger et al., 2005).

\section{Functional analysis}

Identification of types and transmembrane regions of proteins was performed using SOSUI server (Hirokawa et al., 1998). Presence of disulphide bonds and their bonding pattern was predicted using CYS REC tool. Functional domains of TLR proteins were analysed using Simple Modular Architecture Research Tool (SMART) (Schultz et al., 1998).

\section{Secondary structure prediction}

Secondary structures of selected Toll/TLR proteins were predicted using Self-Optimised Prediction Method with Alignment (SOPMA) server (Combet et al., 2000).

\section{Homology modelling}

Modelling of 3D structure of selected proteins was performed using different softwares viz., SWISS-MODEL (Waterhouse et al., 2018), Geno3D (Combet et al., 2002) and Phyre2 (Kelley et al., 2015) server using template structure from Protein Data Bank (PDB). The quality and accuracy of the modelled 3D structures were evaluated using Rampage (Lovell et al., 2002), ProSA (Protein Structure Analysis) (Wiederstein and Sippl, 2007) and ProQ (Protein Quality Predictor) (Cristobal et al., 2001).

\section{Results and discussion}

\section{Physico-chemical and functional characterisation}

Physico-chemical parameters of the selected Toll/ TLR proteins were computed using ExPASyProtParam are tabulated in Table 2. The results of characterisation of physico-chemical properties of proteins suggest that Toll/ TLRs proteins from penaeid shrimps contain relatively more hydrophobic residues. The presence of $22(2.4 \%)$ Cys in ACC68670.1 (P. chinensis), 15 (1.4\%) Cys in ROT75501.1 (P. vannamei), 22 (2.4\%) Cys in ABO38434.1 (P. monodon) and $25(2.5 \%)$ Cys in BAF99007.1 (P. japonicus) shows the presence of disulphide bonds in all the four species. The amino acid composition of Toll/TLRs computed using ExPASyProtParam is given in Table 3. $\mathrm{pI}$ is the value at which the molecule carries no charge or the negative and positive charges are equal. The computed pI value ranges from 4.84 to 5.97 , i.e. $\mathrm{pI}<7$ indicate that these Toll/TLRs proteins are acidic. Computing pI value would be useful for the purification of protein by isoelectric focusing on 2D gel. Total number of positive (Arg+Lys) and negative $(\mathrm{Asp}+\mathrm{Glu})$ residues ranges from 93 to 122 and 104 to 135 respectively. Extinction coefficient of Toll/TLRs ranges from 103555 to 129730 $\mathrm{M}^{-1} \mathrm{~cm}^{-1}$ (assuming all pairs of cysteine residues from cysteines) and 102680 to $128230 \mathrm{M}^{-1} \mathrm{~cm}^{-1}$ (assuming all cysteine residues are reduced). High value of EC indicates the presence of high concentration of cysteine, tryptophan and tyrosine in all the proteins (Gill and Hippel, 1989). Instability index is a measure to estimate the stability of the protein in vitro. A protein with instability index less than 40 is predicted as stable and a value above 40 predicts that the protein may be unstable (Guruprasad et al., 1990). The instability index of Toll/TLRs ranges from 35.68 to 48.26. Hence, it shows that Toll/TLRs from ACC68670.1 $(P$. chinensis $)$ and ROT75501.1 (P. vannamei), ABO38434.1 (P. monodon) are probably stable $(\mathrm{II}<40)$ and Toll protein from BAF99007.1 (P. japonicus) is probably unstable. The aliphatic index of a protein is a measure to estimate thermostability of proteins based on the relative volume occupied by aliphatic side chains (alanine, valine, isoleucine and leucine) (Ikai, 1980). AI of Toll/TLRs ranges from 92.30 to 98.67. The high AI indicates that these proteins are highly thermostable. GRAVY value ranges from -0.169 to -0.288 which indicates hydrophobic nature of protein. 
Table 2. Physico-chemical properties computed using ExPASyProtParam

\begin{tabular}{lllllllll}
\hline Accession No. & No. of amino acids & Mol. Wt. & pI & + R/-R & EC & II & AI & GRAVY \\
\hline ACC68670.1 & 930 & 106321.08 & 5.97 & $94 / 104$ & $119635 / 118260$ & 35.68 & 96.09 & -0.169 \\
ROT75501.1 & 1099 & 124206.60 & 5.94 & $122 / 135$ & $103555 / 102680$ & 38.01 & 92.30 & -0.288 \\
ABO38434.1 & 931 & 106503.35 & 5.68 & $93 / 107$ & $126625 / 125250$ & 36.80 & 96.61 & -0.169 \\
BAF99007.1 & 1009 & 115900.98 & 5.73 & $105 / 121$ & $129730 / 128230$ & 48.26 & 98.67 & -0.191 \\
\hline
\end{tabular}

"EC: The first value is based on the assumption that all pairs of cysteine residues form cysteines and the second value is based on the assumption that all cysteine residues are reduced.

Table 3. Amino acid composition in Toll/TLRs computed using Expasy'sProtParam

\begin{tabular}{|c|c|c|c|c|c|c|c|c|c|}
\hline \multirow[t]{2}{*}{ No. } & \multirow[t]{2}{*}{ Amino acid } & \multicolumn{2}{|c|}{ ACC68670.1 } & \multicolumn{2}{|c|}{ ROT75501.1 } & \multicolumn{2}{|c|}{ ABO38434.1 } & \multicolumn{2}{|c|}{ BAF99007.1 } \\
\hline & & No. & $\%$ & No. & $\%$ & No. & $\%$ & No. & $\%$ \\
\hline 1 & Alanine & 29 & 3.1 & 50 & 4.5 & 29 & 3.1 & 29 & 2.9 \\
\hline 2 & Arginine & 40 & 4.3 & 68 & 6.2 & 37 & 4.0 & 43 & 4.3 \\
\hline 3 & Asparagine & 73 & 7.8 & 72 & 6.6 & 71 & 7.6 & 83 & 8.2 \\
\hline 4 & Aspartic acid & 57 & 6.1 & 62 & 5.6 & 60 & 6.4 & 51 & 5.1 \\
\hline 5 & Cysteine & 22 & 2.4 & 15 & 1.4 & 22 & 2.4 & 25 & 2.5 \\
\hline 6 & Glutamine & 35 & 3.8 & 30 & 2.7 & 36 & 3.9 & 35 & 3.5 \\
\hline 7 & Glutamic acid & 47 & 5.1 & 73 & 6.6 & 47 & 5.0 & 70 & 6.9 \\
\hline 8 & Glycine & 44 & 4.7 & 51 & 4.6 & 40 & 4.3 & 38 & 3.8 \\
\hline 9 & Histidine & 16 & 1.7 & 19 & 1.7 & 15 & 1.6 & 18 & 1.8 \\
\hline 10 & Isoleucine & 56 & 6.0 & 47 & 4.3 & 58 & 6.2 & 68 & 6.7 \\
\hline 11 & Leucine & 130 & 14.0 & 146 & 13.3 & 128 & 13.7 & 133 & 13.2 \\
\hline 12 & Lysine & 54 & 5.8 & 54 & 4.9 & 56 & 6.0 & 62 & 6.1 \\
\hline 13 & Methionine & 20 & 2.2 & 26 & 2.4 & 21 & 2.3 & 13 & 1.3 \\
\hline 14 & Phenylalanine & 55 & 5.9 & 45 & 4.1 & 52 & 5.6 & 57 & 5.6 \\
\hline 15 & Proline & 38 & 4.1 & 51 & 4.6 & 41 & 4.4 & 45 & 4.5 \\
\hline 16 & Serine & 79 & 8.5 & 102 & 9.3 & 80 & 8.6 & 86 & 8.5 \\
\hline 17 & Threonine & 48 & 5.2 & 73 & 6.6 & 47 & 5.0 & 47 & 4.7 \\
\hline 18 & Tryptophan & 15 & 1.6 & 10 & 0.9 & 16 & 1.7 & 16 & 1.6 \\
\hline 19 & Tyrosine & 24 & 2.6 & 32 & 2.9 & 25 & 2.7 & 27 & 2.7 \\
\hline 20 & valine & 48 & 5.2 & 73 & 6.6 & 50 & 5.4 & 63 & 6.2 \\
\hline
\end{tabular}

Functional characterisation of Toll/TLRs was performed using SOSUI for identification of types of proteins. All proteins were classified as transmembrane proteins. Transmembrane regions predicted using SOSUI are tabulated in Table 4. Structural analysis through
SMART revealed that all protein sequences had N-terminal and C-terminal transmembane regions, Leucine rich repeats and TIR (Toll/Interleukin 1 homology receptor) domain at C-terminal end. As an example, the structural feature of TLR from $P$. vannamei is illustrated in Fig. 1.

Table 4. Transmembrane regions of proteins identified using SOSUI server

\begin{tabular}{llllll}
\hline Accession No. & Type of protein & Transmembrane region & Type & Length & N-C terminal \\
\hline ACC68670.1 & Membrane protein & MVLPAFLLWGWAAGGVTLSLSCG & Secondary & 23 & $5-27$ \\
& & MVIVTIVLITVFLLLFALGTMS & Primary & 23 & $711-733$ \\
ROT75501.1 & \multirow{2}{*}{ Membrane protein } & LTALVFGLLVVLVSLSLGAAIRG & Primary & 23 & $6-28$ \\
& & RAIVISTIVSSLLLVASVMVY & Primary & 21 & $898-918$ \\
ABO38434.1 & \multirow{2}{*}{ Membrane protein } & WMVLPAFLLWGWAAGGVTLSLSC & Primary & 23 & $5-27$ \\
& & VIVTIVLITVFLLLFAVLGTMS & Primary & 22 & $713-734$ \\
BAF99007.1 & \multirow{2}{*}{ Membrane protein } & PLWILLPCFLVVSSIVTGVWGFG & Primary & 23 & $3-25$ \\
& & LPPVIIASTVISMFLILSGVLA & Primary & 23 & $786-808$
\end{tabular}




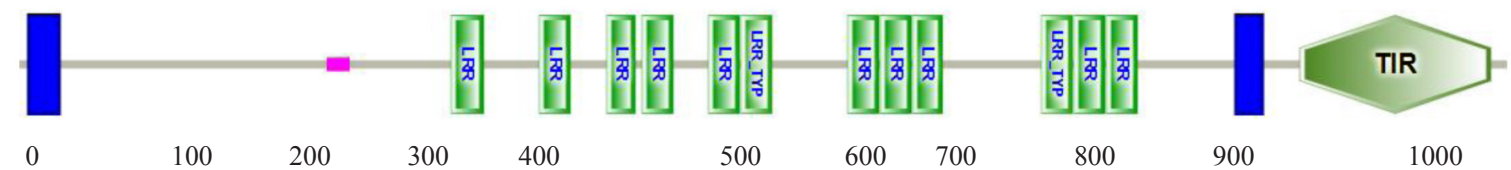

Fig. 1. Domain topology of TLRs from P. vannamei

Presence of disulphide bonds and their banding pattern was predicted using CYS_REC tool which revealed that Toll/TLRs from all the 4 species of penaeid shrimps have most probable pattern of cysteine residue pairing (Table 5).

\section{Prediction of secondary structure}

The secondary structures of Toll/TLRs were predicted using SOPMA. The calculated secondary structure elements are tabulated in Table 6 . The results revealed that alpha helices and random coils were predominant among secondary structure elements, followed by extended strand and beta turn while all other secondary structure elements such as $3_{10}$ helix, Pi helix (Ti), Beta bridge, Beta region and Ambiguous states were not found in all Toll/TLRs.

\section{Homology modelling and validation}

Homology modelling is modelling a protein's 3D structure using a known experimental structure of a homologous protein. The use of this method is based on the observation that two proteins belonging to the same family will have similar three-dimensional structures (Vyas et al., 2012). Homology models of proteins are useful when no experimental $3 \mathrm{D}$ structure is available. Modelling of 3D structures of Toll/TLRs was performed using SWISS-MODEL, Geno3D and Phyre2 based on the templates selected from PDB. Final structures of the models are shown in Fig. 2. Steorochemical quality and accuracy of the predicted models was verified using RAMPAGE. The results revealed that proteins modelled using SWISS MODEL server has maximum residues in favoured regions, from 86.7 to $90.1 \%$ and minimum
Table 5. Most probable pattern of pairs of disulphide bond computed using CYS_REC

\begin{tabular}{lll}
\hline Accession No. & CYS_REC & \\
\hline ACC68670.1 & Cys26-Cys533 & Cys480-Cys538 \\
& Cys29-Cys74 & Cys544-Cys914 \\
& Cys38-Cys542 & Cys662-Cys688 \\
& Cys478-Cys798 & Cys664-Cys704 \\
\hline ROT75501.1 & Cys201-Cys846 & Cys421-Cys1018 \\
& Cys258-Cys844 & Cys500-Cys952 \\
\hline ACC68670.1 & Cys27-Cys39 & Cys534-Cys663 \\
& Cys30-Cys545 & Cys539-Cys689 \\
& Cys479-Cys799 & Cys543-Cys665 \\
\hline BAF99007.1 & Cys27-Cys619 & Cys588-Cys740 \\
& Cys30-Cys621 & Cys610-Cys876 \\
& Cys60-Cys550 & Cys615-Cys742 \\
& Cys189-Cys199 & \\
\hline
\end{tabular}

residues in outlier regions, from 1.9 to $2.4 \%$. Comparison of results obtained from different modelling servers (Table 7) indicates that the model generated using SWISSMODEL is more acceptable.

Validation of the predicted models was performed using ProSA and ProQ and the results are presented in Table 8. LG score values of models predicted using SWISS-MODEL indicate extremely good quality ( $>4.0)$, whereas models predicted using Geno3D and Phyre2 were found to be fairly good $(>2.5)$. MaxSub values indicate fairly good quality $(>0.1)$ of all the models predicted by both the servers (Cristobal et al., 2001). The $\mathrm{Z}$ scores computed using ProSA ranges from -6.4 to -9.54 for models predicted by SWISS-MODEL (Fig. 2b). It is understood that the value falls almost within

Table 6. Secondary structure elements (\%) of TLRs of shrimps using SOPMA

\begin{tabular}{lllll}
\hline Element & ACC68670.1 & ROT75501.1 & ACC68670.1 & BAF99007.1 \\
\hline Alpha helix & 43.98 & 45.40 & 44.79 & 45.00 \\
$3_{10}$ helix & 0 & 0 & 0 & 0 \\
Pi helix & 0 & 0 & 0 & 0 \\
Beta bridge & 0 & 0 & 0 & 0 \\
Extended strand & 15.16 & 12.65 & 15.36 & 13.78 \\
Beta turn & 2.80 & 4.00 & 3.76 & 2.78 \\
Beta region & 0 & 0 & 0 & 0 \\
Random coil & 38.06 & 37.94 & 36.09 & 38.45 \\
Ambiguous states & 0 & 0 & 0 & 0 \\
Other states & 0 & 0 & 0 & 0 \\
\hline
\end{tabular}


Table 7. Ramachandran plot calculation using RAMPAGE

\begin{tabular}{lllll}
\hline Server & Accession No. & Residues in favoured region (\%) & Residues in allowed region (\%) & Residues in outlier region (\%) \\
\hline \multirow{2}{*}{ SWISS MODEL } & ACC68670.1 & 89.3 & 8.8 & 1.9 \\
& ROT75501.1 & 86.7 & 8.1 & 2.4 \\
& ACC68670.1 & 89.2 & 6.8 & 2.1 \\
& BAF99007.1 & 90.1 & 7.3 & 2.3 \\
\hline Geno3D & ACC68670.1 & 72.3 & 22.9 & 4.8 \\
& ROT75501.1 & 68.1 & 26.8 & 5.0 \\
& ACC68670.1 & 55.6 & 30.8 & 13.6 \\
& BAF99007.1 & 52.5 & 32.9 & 14.5 \\
\hline Phyre2 & ACC68670.1 & 88.5 & 7.9 & 3.6 \\
& ROT75501.1 & 85.5 & 12.1 & 5.2 \\
& ACC68670.1 & 88.8 & 9.1 & 3.9 \\
& BAF99007.1 & 89.3 & 8.4 & 2.6 \\
\hline
\end{tabular}

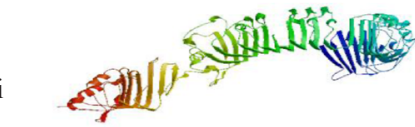

ii

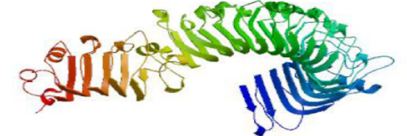

iii

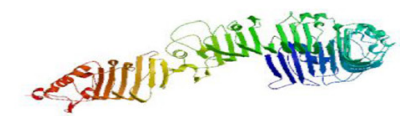

iv

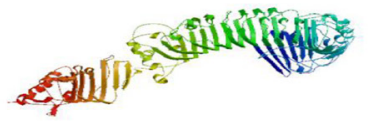

(a)
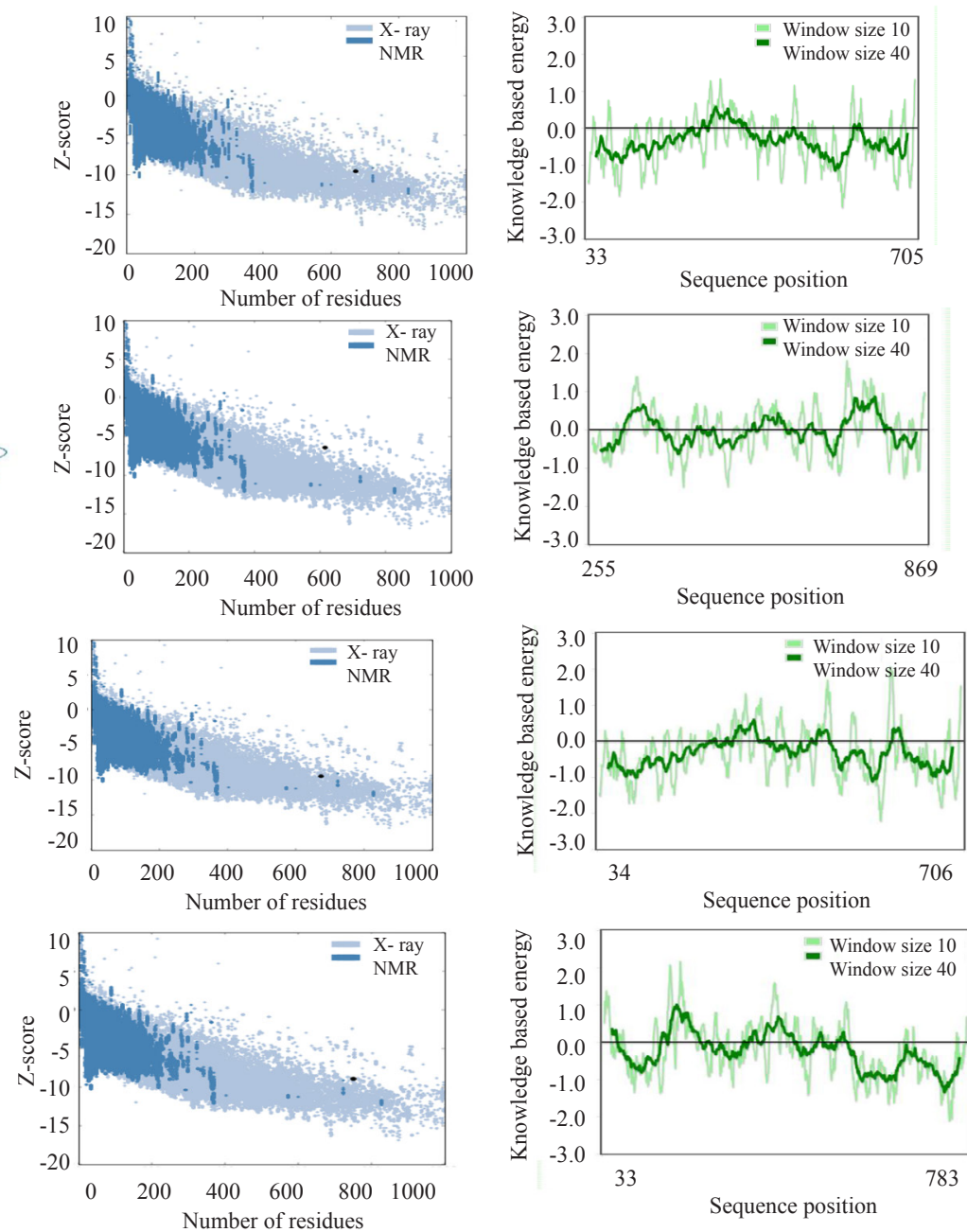

(b)

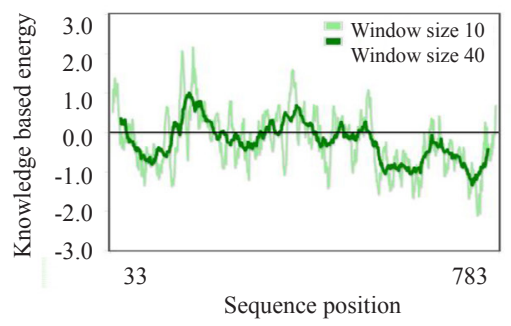

(c)

Fig. 2. Toll/TLRs from (i) P. chinensis (ACC68670.1), (ii) P. vannamei (ROT75501.1), (iii) P. monodon (ACC68670.1), (iv) P. japonicus (BAF99007.1). (a) Homology modeled 3D structures computed using SWISS MODEL; (b) ProSA web Z-scores of protein chain in PDB determined by X-ray crystallography (light blue) NMR spectroscopy (dark blue) by their length; (c) Plot of residue scores 
Table 8. Validation of protein 3D model computed using ProSA and ProQ

\begin{tabular}{lllllll}
\hline Server & Accession No. & Template ID & Seq. Identity (\%) & Z score & LG score & MaxSub \\
\hline SWISS MODEL & ACC68670.1 & $4 \mathrm{lxr}$ & 25.00 & -9.54 & 4.827 & 0.338 \\
& ROT75501.1 & $4 \mathrm{lxr}$ & 19.41 & -6.4 & 4.189 & 0.278 \\
& ACC68670.1 & $4 \mathrm{xrr}$ & 25.53 & -9.44 & 4.994 & 0.353 \\
& BAF99007.1 & $4 \mathrm{xrr}$ & 27.41 & -8.89 & 4.542 & 0.335 \\
\hline Geno3D & ACC68670.1 & $4 \mathrm{xs}$ & 21.8 & -9.24 & 4.123 & 0.289 \\
& ROT75501.1 & $2 \mathrm{a} 0 \mathrm{z}$ & 21.30 & -5.31 & 3.917 & 0.249 \\
& ACC68670.1 & $4 \mathrm{lxs}$ & 22.50 & -4.93 & 3.466 & 0.205 \\
& BAF99007.1 & $4 \mathrm{lxr}$ & 24.20 & -4.75 & 3.787 & 0.228 \\
\hline Phyre2 & ACC68670.1 & $4 \mathrm{xr}$ & 23.00 & -6.91 & 3.436 & 0.283 \\
& ROT75501.1 & $4 \mathrm{xr}$ & 19.00 & -4.4 & 2.977 & 0.211 \\
& ACC68670.1 & $41 \mathrm{xr}$ & 24.00 & -6.74 & 3.162 & 0.261 \\
& BAF99007.1 & $4 \mathrm{lxr}$ & 24.00 & -7.36 & 3.755 & 0.284 \\
\hline
\end{tabular}

the range of scores typically found for native proteins of similar size. The plot of residue scores predicted using ProSA shows local model quality by plotting energies as a function of amino acid sequence position (Fig. 2c). Plot revealed predominantly negative values, indicating good quality of the predicted model. In general, positive values correspond to problematic or erroneous parts of the input structure (Wiederstein and Sippl, 2007).

It has been reported that TLR agonists could be exploited as adjuvants to enhance immune responses during vaccination (De-Gregorio et al., 2013). Administration of TLR agonists provided rapid induction of innate resistance to infectious challenge by different pathogens (Cluff et al., 2005). TLR agonists can also be used as immunomodulating agents to directly target the host rather than pathogen (Mifsud et al., 2014). The precise pattern of immune receptors activated by ligands is likely to be extremely important in determining the ultimate immune outcome (Petrovsky and Cooper, 2011). So, the models predicted using homology modelling would serve to guide the design of more potent ligand or TLR agonist. Using the $3 \mathrm{D}$ structure, the predominant binding modes of a ligand with a protein could be predicted and therefore the results of this study would aid in computer aided design of TLR agonists.

\section{Acknowledgements}

Authors acknowledge Institute of Fisheries PostGraduate Studies, TNJFU, Tamil Nadu for providing bioinformatics laboratory facilities to carry out the present work.

\section{References}

Arts, J. A., Cornelissen, F. H., Cijsouw, T., Hermsen, T., Savelkoul, H. F. and Stet, R. J. 2007. Molecular cloning and expression of a Toll receptor in the giant tiger shrimp,
Penaeus monodon. Fish Shellfish Immunol., 23: 504-513. DOI: 10.1016/j.fsi.2006.08.018.

Beutler, B. 2004. Innate immunity: an overview. Mol. Immunol., 40: 845-859. DOI: 10.1016/j.molimm.2003.10.005

Chen, Y., Cao, J. and Zhang, X. 2016. The role of cytokine PF4 in the antiviral immune response of shrimp. PLOS ONE, 11(9): e0162954. doi.org/10.1371/journal.pone.0162954.

Cluff, C. W., Baldridge, J. R., Stover, A. G., Evans, J. T., Johnson, D. A., Lacy, M. J., Clawson, V. G., Yorgensen, V. M., Johnson, C. L., Livesay, M. T., Hershberg, R. M. and Persing, D. H. 2005. Synthetic toll-like receptor 4 agonists stimulate innate resistance to infectious challenge. Infect Immun., 73(5): 3044-3052.

Combet, C., Blanchet, C., Geourjon, C. and Deleage, G. 2000. NPS@: Network Protein Sequence Analysis. TIBS, 25(3): 147-150. DOI:10.1016/s0968-0004(99)01540-6.

Combet, C., Jambon, M., Deleage, G. and Geourjon, C. 2002. Geno3D - an automated protein modelling web server. Bioinformatics, 18: 213-214. DOI: 10.1093/ bioinformatics/18.1.213.

Cristobal, S., Zemla, A., Fischer, D., Rychlewski, L. and Elofsson, A. 2001. ProQ: A study of quality measures for protein threading models. BMC Bioinformatics, 2(1): 5.

Dechamma, M., Rajeish, M., Maiti, B., Mani, M. K. And Karunasagar, I. 2015. Expression of Toll-like receptors (TLR), in lymphoid organ of black tiger shrimp (Penaeus monodon) in response to Vibrio harveyi infection. Aquac. Rep., 1: 1-4. DOI10.1016/j.aqrep.2015.02.002.

Deepika, A., Sreedharan, K., Paria, A., Makesh, M. and Rajendran, K. V. 2014. Toll-pathway in tiger shrimp (Penaeus monodon) responds to white spot syndrome virus infection: evidence through molecular characterisation and expression profiles of MyD88, TRAF6 and TLR genes. Fish Shellfish Immunol., 41(2): 441-454. DOI: 10.1016/j. fsi.2014.09.026.

De-Gregorio, E., D’Oro, U., Bertholet, S. and Rappuoli, R. 2013. Vaccines. In: Paul, W. E. (Eds.), Fundamental immunology. 
Lippincott Williams and Wilkins, a Wolters Kluwer Business, Philadelphia, p. 1032-1068.

Gasteiger, E., Hoogland, C., Gattiker, A., Duvaud, S., Wilkins, M. R., Appel, R. D. and Bairoch 2005. A protein identification and analysis tools on the ExPASy Server: In: Walker, J. M. (Eds.), The proteomics protocol handbook. Humana Press, USA, p. 571-607.

Gill, S. C. and Hippel, P. H. V. 1989. Calculation of protein extinction coefficients from amino acid sequence data. Anal Biochem., 182: 319-326. DOI: 10.1016/00032697(89)90602-7.

Guruprasad, K., Reddy, B. V. B. and Pandit, M. W. 1990. Correlation between stability of a protein and its dipeptide composition: a novel approach for predicting in vivo stability of a protein from its primary sequence. Protein Eng., 4: 155-161. DOI: 10.1093/protein/4.2.155.

Hirokawa, T., Boon-Chieng, S. and Mitaku, S. 1998. SOSUI: classification and secondary structure prediction system for membrane proteins. Bioinformatics, 14: 378-9. DOI: 10.1093/bioinformatics/14.4.378.

Ikai, A. J. 1980. Thermostability and aliphatic index of globular proteins. J. Biochem., 88: 1895-1898. doi.org/10.1093/ oxfordjournals.jbchem.a133168.

Karunasagar, I. 1994. Mass mortality of Penaeus monodon larvae to antibiotic resistant Vibrio harveyi infection. Aquaculture, 128: 203-209. doi.org/10.1016/0044-8486(94)90309-3.

Kelley, L. A., Mezulis, S., Yates, C. M., Wass, M. N. and Sternberg, M. J. 2015. The Phyre2 web portal for protein modeling, prediction and analysis. Nat. Protoc., 10(6): 845-58. . DOI: 10.1038/nprot.2015.053.

Krishnan, J., Lee, G. and Choi, S. 2009. Drugs targeting toll-like receptors. Arch. Pharmacal. Res., 32(11): 1485-1502. doi: 10.1007/s12272-009-2100-6.

Kyte, J. and Doolittle, R. F. 1982. A simple method for displaying the hydropathic character of a protein. J. Mol. Biol., 157: 105-132. DOI: 10.1016/0022-2836(82)90515-0.

Loker, E. S., Adema, C. M., Zhang, S. M. and Kepler, T. B. 2004. Invertebrate immune systems - not homogeneous, not simple, not well understood. Immunol. Rev., 198: 10-24. DOI: $10.1111 / \mathrm{j} .0105-2896.2004 .0117 . x$.

Lovell, S. C., Davis, I. W., Arendall, W. B., de-Bakker, P. I., Word, J. M., Prisant, M. G., Richardson, J. S. and Richardson, D. C. 2002. Structure validation by Calpha geometry: phi, psi and Cbeta deviation. Proteins Struct. Funct. Bioinf., 50: 437-450. DOI: 10.1002/prot.10286.

Mekata, T., Kono, T., Yoshida, T., Sakai, M. and Itami, T. 2008. Identification of cDNA encoding Toll receptor, MjToll gene from kuruma shrimp, Marsupenaeus japonicus. Fish Shellfish Immunol., 24: 122-133. doi: 10.1016/j. fsi.2007.10.006. Epub 2007 Oct 25.

Mifsud, E. J., Tan, A. C. L. and Jackson, D. C. 2014. TLR agonists as modulators of the innate immune response and their potential as agents against infectious disease. Front. Immunol., 5: 79 .

Patel, M. C., Shirey, K. A., Pletneva, L. M., Boukhvalova, M. S., Garzino-Demo, A., Vogel, S. N. and Blanco, J. C. 2014. Novel drugs targeting Toll-like receptors for antiviral therapy. Future Virol., 9(9): 811-829. DOI: 10.2217/ fvl.14.70.

Petrovsky, N. and Cooper, P. D. 2011. Carbohydrate-based immune adjuvants. Expert Rev. Vaccines, 10(4): 523-537. doi: $10.1586 /$ erv.11.30.

Schultz, J., Milpetz, F., Bork, P. and Ponting, C. P. 1998 SMART, a simple modular architecture research tool: Identification of signaling domains. PNAS, 95: 5857-5864. DOI: $10.1073 /$ pnas.95.11.5857.

Vyas, V. K., Ukawala, R. D., Ghate, M. and Chintha, C. 2012. Homology modeling - a fast tool for drug discovery: current perspectives. Indian J. Pharm. Sci., 74(1): 1-17. doi: 10.4103/0250-474X.102537.

Wang, P. H., Liang, J. P., Gu, Z. H, Wan, D. H., Weng, S. P., Yu, X. Q. and He, J. G. 2012. Molecular cloning, characterisation and expression analysis of two novel Tolls (LvToll2 and LvToll3) and three putative Spatzle-like Toll ligands (LvSpzle3) from Litopenaeus vannamei. Dev. Comp Immunol., 36: 359-371. DOI: 10.1016/j.dci.2011.07.007.

Wang, X. W. and Wang, J. X. 2013. Pattern recognition receptors acting in innate immune system of shrimp against pathogen infections. Fish Shellfish Immunol., 34(4): 981-989. DOI: 10.1016/j.fsi.2012.08.008.

Waterhouse, A., Bertoni, M., Bienert, S., Studer, G., Tauriello, G., Gumienny, R., Heer, F. T., de-Beer, T. A. P., Rempfer, C., Bordoli, L., Lepore, R. and Schwede, T. 2018. SWISSMODEL: homology modelling of protein structures and complexes. Nucleic Acids Res., 46(1): 296- 303. DOI: 10.1093/nar/gky427.

Wiederstein, M. and Sippl, M. J. 2007. ProSA-web: interactive web service for the recognition of errors in threedimensional structures of proteins. Nucleic Acids Res., 35: 407-410. DOI: $10.1093 / \mathrm{nar} / \mathrm{gkm} 290$.

Yang, C., Zhang, J., Li, F., Ma, H., Zhang, Q., Priya, J. T. A., Zhang, X. and Xiang, J. 2008. A toll receptor from Chinese shrimp Fenneropenaeus chinensis is responsive to Vibrio anguillarum infection. Fish Shellfish Immunol., 24: 564-574. DOI: 10.1016/j.fsi.2007.12.012.

Date of Receipt $\quad$ : 07.06.2019

Date of Acceptance : 27.01 .2020 